\title{
Modified halloysite as a filler for epoxy resins
}

\author{
Izabella Legocka, Ewa Wierzbicka, Talal J.M. Al-Zahari, Osazuwa Osawaru \\ Industrial Chemistry Research Institute, ul. Rydygiera 8, 01-793 Warszawa, Poland, e-mail: izabella.legocka@ichp.pl
}

\begin{abstract}
The modification methods of halloysite and further applications of the modified mineral as a filler for epoxy resins have been presented. The advantage of ultrasound treatment prior to chemical modification with an organic compound in order to obtain a hybrid filler was confirmed. The analysis of the composites obtained with the use of the modified halloysite (3-5 wt.\% range) as a filler for epoxy resins indicates an improved interphase interaction and mechanical properties in comparison to the composites based on neat halloysite.
\end{abstract}

Keywords: layered-tubular mineral, chemical modification, modification with ultrasounds, fillers, filling of epoxy resins, mechanical and thermal properties.

\section{INTRODUCTION}

Halloysite is a volcanic layered mineral of the formula $\mathrm{Al}_{2} \mathrm{Si}_{2} \mathrm{O}_{5}(\mathrm{OH})_{4}$ which is characterized by high porosity and a relativity large surface area, as well as good ionexchange properties and susceptibility to chemical and mechanical treatment. It also possesses a migre crystallite structure, about $30 \%$ of which constitutes stiff straight nanotubes in the layered structure. Halloysite occurring in Poland can by modified for applications as an active filler. The introduction of adequate modification procedures (ultrasound and chemical) enables the applications as a filler-modifier for a wide range of polymers, especially epoxy resins ${ }^{1}$.

The first modification stage of the treatment of the mineral with ultrasound was performed for the purpose of the generation of structural defects on the crystallographic surface. It is assumed that the formed defects will be active centers for coupling of organic compounds used for surface modification. As a result of this interaction, an organic layer is formed on the surface of the layer leading to the formation of the hybrid structure that can be dispersed better in the polymeric matrix and thereby promote interphase adhesion in the filled polymer ${ }^{2}$. The choice of organic compound used in the modification was made by taking into consideration the possibility of an active interaction with the specific polymeric matrix. The effect of the modification was measured by spectroscopic and thermal analysis. The evaluation of the influence of the modification and the affinity to agglomeration of the particles is possible with the use of electrophoretic mobility analysis (Zeta Potential $[\xi]$ ). The Zeta Potential is a part of the difference in potential generated at the phase border caused by the occurrence of a double electrical layer. It is used as a criterion to determine the stability of the dispersed systems, thereby allowing the selection of appropriate organic compound and its concentration. A preliminary evaluation of dispergation of the filler in the epoxy matrix was performed by electron microscopy (SEM and SEM-EDS) analysis. The applicability to fill and modify epoxy resins was evaluated by the mechanical properties analysis of these composites.

\section{EXPERIMENTAL}

\section{Materials}

Halloysite (fraction FLS from a fluidized bed reactor) was obtained from Dunino mines in Poland. Colophony abietic acid $\left(\mathrm{Tm}=74^{\circ} \mathrm{C}, \mathrm{AN}=179 \mathrm{mg} \mathrm{KOH} / \mathrm{g}\right)$ was obtained from HCM Kłobudzk-Poland. Glycydyl methacrylate (GMA; M = $142.2 \mathrm{~g} / \mathrm{mol}, \rho=1.07 \mathrm{~g} / \mathrm{cm}^{3}$ ) and consumption gelatin were obtained from Aldrich and used as received. The zinc salt of ethylene - methacrylic acid copolymer (Surlyn $1857-\rho=0.94 \mathrm{~g} / \mathrm{cm}^{3}, \mathrm{Tm}=87^{\circ} \mathrm{C}$, $\left.\operatorname{MFR}_{\left(190^{\circ} \mathrm{C} / 2.16 \mathrm{~kg}\right)}=4.0 \mathrm{~g} / 10 \mathrm{~min}\right)$ and the oligocyclopentadiene resin (Escorez $5380-\mathrm{Tm}=85{ }^{\circ} \mathrm{C}, \eta_{150^{\circ} \mathrm{C}}=$ $250 \mathrm{mPa} \cdot \mathrm{s}, \rho=1.1 \mathrm{~g} / \mathrm{cm}^{3}$ ) were obtained from Dupont and Eastmann respectively, while the epoxy resin (Epidian 5) and triethylenetetraamine were received from Z.Ch."Organika Sarzyna" in Nowa Sarzyna, Poland.

\section{Applied analytical methods:}

In the evaluation of halloysite and epoxy resin modification:

- IR spectra were recorded from a $\mathrm{KBr}$ pellets on a Perkin Elmer 7 Instrument ;

- The thermal properties of the fillers and composites were measured with a TGA Q50 V20.8 Instrument thermogravimetry analyzer. The sample weigh varied from 10 to $15 \mathrm{mg}$. Samples were heated from ambient temperature to $700^{\circ} \mathrm{C}$ at a rate of $10^{\circ} \mathrm{C} / \mathrm{min}$ in nitrogen atmosphere.

- DSC thermograms were measured with a Perkin Elmer Instrument at a linear heating rate of $10^{\circ} \mathrm{C} / \mathrm{min}$. The sample mass was ca. $10 \mathrm{mg}$. During a first scan, the samples were heated to $150{ }^{\circ} \mathrm{C}$ and cooled at $10^{\circ} \mathrm{C} / \mathrm{min}$ to $-75^{\circ} \mathrm{C}$; during the second scan, the samples were heated again to $150{ }^{\circ} \mathrm{C}$. The Tg-values of epoxy resin reported here were obtained from the second scan.

- The particle size and ZETA potential of fillers were measured with a Malvern Instruments Ltd. UK Zeta Sizer using Photon Correlation Spectroscopy method (PCS);

- SEM micrographs were obtained with the help of JEOL JSM - 6490LV at 2000X magnification. The composition specimen fractured pieces were mounted on the SEM Stubs and gold coated for observation in a SEM.

- Standard tensile was performed using a INSTRON 3345 machine with a cross-head speed of $5 \mathrm{~mm} / \mathrm{min}$ at room temperature ${ }^{3}$. The flexural strength test was performed 
using the same INSTRON machine at room temperature. The test procedure followed norms ${ }^{\mathbf{4}, 5}$. The dimensions of the test specimens were $80 \mathrm{~mm} \times 10 \mathrm{~mm}$ x $4 \mathrm{~mm}$. The cross-head speed was $2 \mathrm{~mm} / \mathrm{min}$. Charpy impact strength tests were performed on an impact tester (Zwick 5012) with pendulum energy of $2 \mathrm{~J}$ and a span of $60 \mathrm{~mm}$. The test procedure followed norms ${ }^{6}$.

\section{Halloysite modification method:}

The first stage involved the preliminary treatment of virgin halloysite fraction with $35 \mathrm{kHz}$ for $2-3 \mathrm{~h}$ ultrasound frequency. The hypothetical amount of organic compound used for halloysite modification was derived from the formula for the ion-exchange of layered alumina-silicates ${ }^{7}$ : $\mathrm{X}=\frac{\mathrm{CEC}}{100} \times 50 \times \frac{\mathrm{M}}{1000}$ where:

$\mathrm{X}$ - the amount of modifying organic compound

CEC - the cationic volume characteristic for specific alumina-silicate ( 55 for halloysite)

$\mathrm{m}$ - molecular weight of organic compound

50 - amount of halloysite to be modified

In practice, the amount of organic compounds was 1015 wt. $\%$ of organic compound per 100 wt. $\%$ of neat halloysite. In the second stage the organic compound (colophony- abietic acid, GMA, gelatin, Surlyn 1857 or Escorez 5380) dissolved earlier in acetone or n-heptane or water was placed in a glass reactor and the halloysite was added in portions. The conditions of the modification were ranging from $60^{\circ} \mathrm{C}$ to $120^{\circ} \mathrm{C}$ within 1 to $3 \mathrm{~h}$. The obtained product was separated from the unreacted monomer and the solvent evaporated to obtain the final modified halloysite. The names of the obtained modified fillers are presented in table 1 .

Table 1. Name of modifier

\begin{tabular}{|l|c|}
\hline Name & Type of modifying compound \\
\hline H & -- \\
\hline HU & Ultrasound \\
\hline HUC & Colophony \\
\hline HUG & Gelatin \\
\hline HUOCPD & Escorez 5380 resin \\
\hline HUS & Surlyn 1857 resin \\
\hline HUGMA & Glycydyl methacrylate \\
\hline
\end{tabular}

\section{Modification of the epoxy resins}

A measured amount of epoxy resin and the modified halloysite were placed in a $250 \mathrm{ml}$ beaker and heated to $70^{\circ} \mathrm{C}$ for $1 \mathrm{~h} 3$ and $5 \mathrm{wt} . \%$ of the modified halloysite per 100 wt.\% of the epoxy resin and stirred vigorously for 3-5 min with 12 wt. $\%$ of TECZA at $30^{\circ} \mathrm{C}$. A homogeneous product was obtained and poured into moulds of bars and dumbbells, cured for $14 \mathrm{~h}$ at $25^{\circ} \mathrm{C}$ and then dried in the postcuring process for $2 \mathrm{~h}$ at $90{ }^{\circ} \mathrm{C}$.

\section{RESULTS}

\section{Characteristics of the modified halloysite}

\section{FTIR spectroscopy}

A series of shifts of characteristic wavebands of particular groups of the modifying organic compound and filler was observed:
- a shift from $1706 \mathrm{~cm}^{-1}$ (carbonyl group of the resin) to $1700 \mathrm{~cm}^{-1}$ in the zinc salt of the copolymer ethylenemethacrylic acid;

- a shift from $826 \mathrm{~cm}^{-1}$ (cyclic structure) to $840 \mathrm{~cm}^{-1}$ for the oligocyclopentadiene resin;

- a shift $1649.9 \mathrm{~cm}^{-1}$ (carbonyl group in abietic acid) to $1698 \mathrm{~cm}^{-1}$ in the abietic acid;

- a shift from $1721 \mathrm{~cm}^{-1}$ (acrylic group) to $1712 \mathrm{~cm}^{-1}$ in GMA;

- a shift from $1670 \mathrm{~cm}^{-1}$ (carbonyl group) to $1653 \mathrm{~cm}^{-1}$ and also from $1550 \mathrm{~cm}^{-1}$ (amine group) to $1557 \mathrm{~cm}^{-1}$ in gelatin;

- a shift from $467 \mathrm{~cm}^{-1}$ (Si-O) to $469 \mathrm{~cm}^{-1}, 1033 \mathrm{~cm}^{-1}$ (Si-O-Si) to $1035 \mathrm{~cm}^{-1}, 536 \mathrm{~cm}^{-1},(\mathrm{Al}-\mathrm{O})$ to $531 \mathrm{~cm}^{-1}$ in halloysite;

The above-mentioned changes of characteristic wavebands indicate an active interaction between the modifying organic compound and the mineral-halloysite to obtain an active modified filler.

\section{Thermogravimetry}

In comparison with the virgin starting materials, changes in the melting and glass points were observed for the compounds in the halloysite/organic compound composite. The endothermic effect for halloysite modified by colophony and Escoreze 5380 resin was observed. It is connected with the melting of organic compound being on the surface of halloysite. With reference to other simples ( HUG, HUS and HUGMA) the exothermic effect was reported. Changes in the maximum degradation temperature and weight loss at this temperature of the obtained fillers were also observed. It turned out slightly lower than the temperature of the unmodified filler and was ranging from $2^{\circ} \mathrm{C}$ to $42^{\circ} \mathrm{C}$. Key changes were also noticed in weight loss. Table 2 shows that the weight loss of the modified halloysite increased from $17 \%$ (neat halloysite) to $39 \%$ (halloysite modified by colophony or Escorez 5380 resin) and 28\% (halloysite modified by gelatin) and $24 \%$ (halloysite modified by glycydyl methacrylate). This probably indicates that various amounts of the organic compound were "bonded" with halloysite.

\section{Zeta Potential and particle size}

A decrease in the Zeta Potential and particle size was observed during the preliminary physical treatment of halloysite, which proved to be advantageous in the polymer filling process. Further chemical modification is leading to differences in both the Zeta Potential and the particle size whose values were higher in comparison to the unmodified halloysite. This is most probably due to the deposition of an organic layer on the surface of the filler and "glueing".

\section{SEM/EDS analysis}

SEM images coupled with EDS microanalysis of the obtained fillers confirm the modification results. Carbon was observed on the surfaces of the samples indicating the presence of the organic compound. Bonded particles of the filler and separated plates/nanotubes were observed. This also indicated a high probability of good dispergation in the epoxy polymer matrices. 
Table 2. Thermal properties of obtain fillers

\begin{tabular}{|l|c|c|c|}
\hline \multirow{2}{*}{ Name of modifier } & \multicolumn{1}{|c|}{ DSC } & \multicolumn{2}{|c|}{ TG } \\
\cline { 2 - 4 } & \multicolumn{1}{|c|}{\begin{tabular}{c}
$\left.{ }^{\circ} \mathrm{C}\right]$ \\
\cline { 2 - 4 }
\end{tabular}} & $\begin{array}{c}\text { Weight loss } \\
\text { in } 700\left[{ }^{\circ} \mathrm{C}\right],[\%]\end{array}$ \\
\hline H & $86.0^{*}$ & 472.0 & 17.0 \\
\hline HU & $79.0^{*}$ & 464.0 & 17.0 \\
\hline HUC & $95.0^{*}$ & 449.0 & 39.0 \\
\hline HUG & $64.0(\mathrm{Tg}) \mathrm{i} 120.0(\mathrm{Tm})^{\star *}$ & 444.0 & 28.0 \\
\hline HUS & $62.0(\mathrm{Tg}) \mathrm{i} 110.0(\mathrm{Tm})^{* *}$ & 470.0 & 21.0 \\
\hline HUOCPD & $80.0^{*}$ & 430.0 & 39.0 \\
\hline HUGMA & $68.0^{* *}$ & 465.0 & 24.0 \\
\hline
\end{tabular}

*endothermic effect

** exothermic effect

Table 3. Properties of particle of obtain fillers

\begin{tabular}{|l|c|c|}
\hline $\begin{array}{l}\text { Name of } \\
\text { modifier }\end{array}$ & $\begin{array}{c}\text { Particle size } \\
{[\mathrm{nm}]}\end{array}$ & $\begin{array}{l}\text { ZETA } \\
\text { potential } \\
{[\mathrm{mV}] \mathrm{pH}=5,4}\end{array}$ \\
\hline $\mathrm{H}$ & 370 & -27.0 \\
\hline $\mathrm{HU}$ & $345-450$ & -26.0 \\
\hline $\mathrm{HUC}$ & $450-650$ & -28.0 \\
\hline HUG & $650-940$ & -32.0 \\
\hline HUS & $750-1270$ & -21.0 \\
\hline HUOCPD & $\begin{array}{c}60-230, \\
\text { (agglomerate max. ok. } \\
20 \mu \mathrm{m})\end{array}$ & +0.2 \\
\hline HUGMA & 650 & -20.0 \\
\hline
\end{tabular}

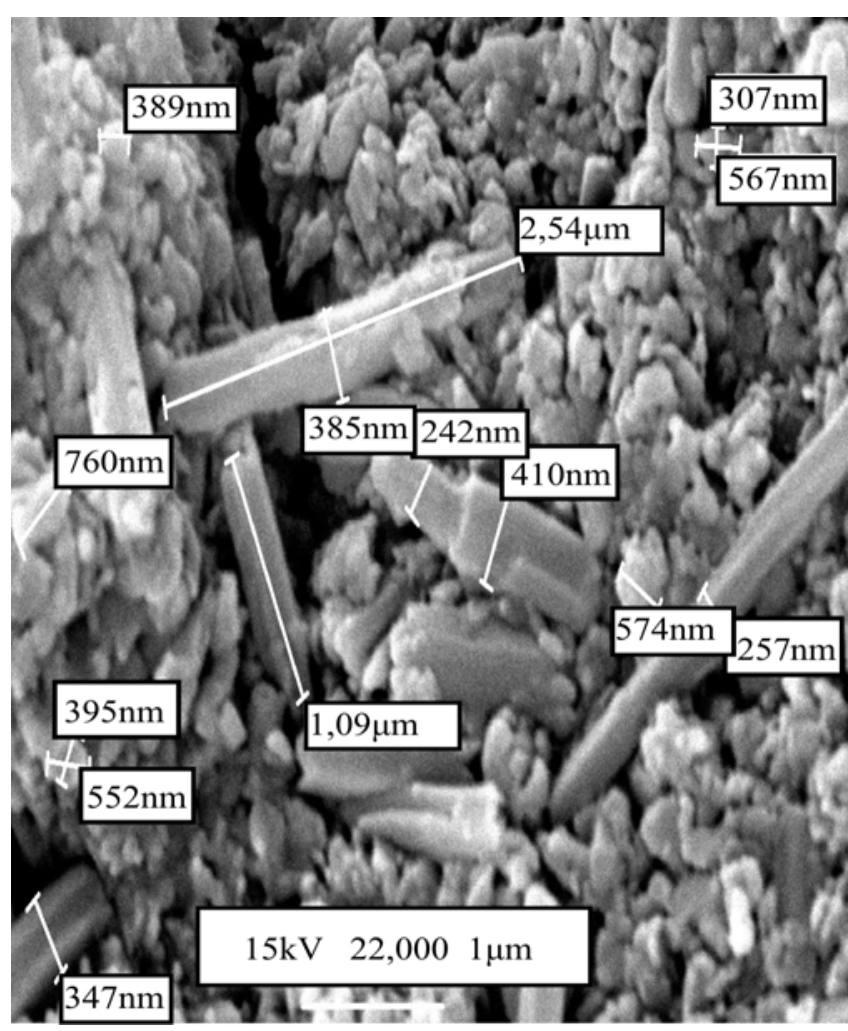

Figure 1. SEM image of natural halloysite

Characterization of properties of epoxy resin/modified halloysite composites

\section{Thermal properties}

The glass transition temperatures ( $\mathrm{Tg}$ ) of the neat epoxy and the composites were determined using DSC. As shown in Table 4, the Tg of the epoxy composites increased. The change in Tg associated with the incorporation of inorganic fillers is a consequence of a rigid-phase reinforcement and destroying of the epoxy network structure. The analysis

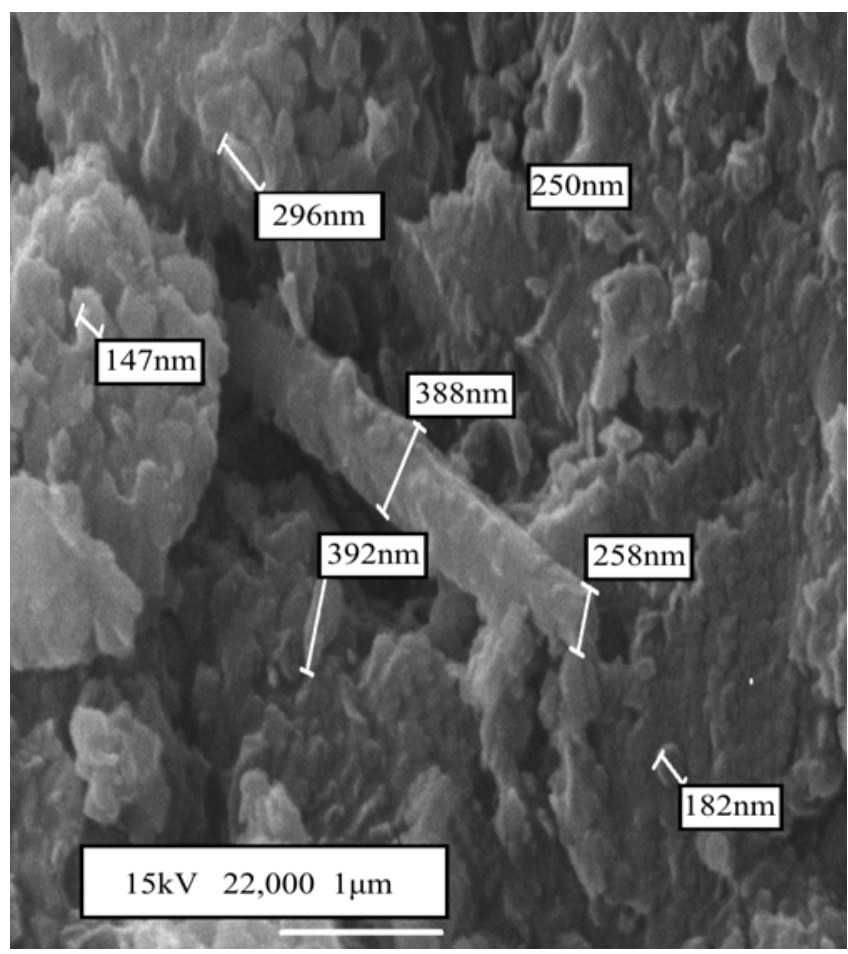

Figure 2. SEM image of HUC filler

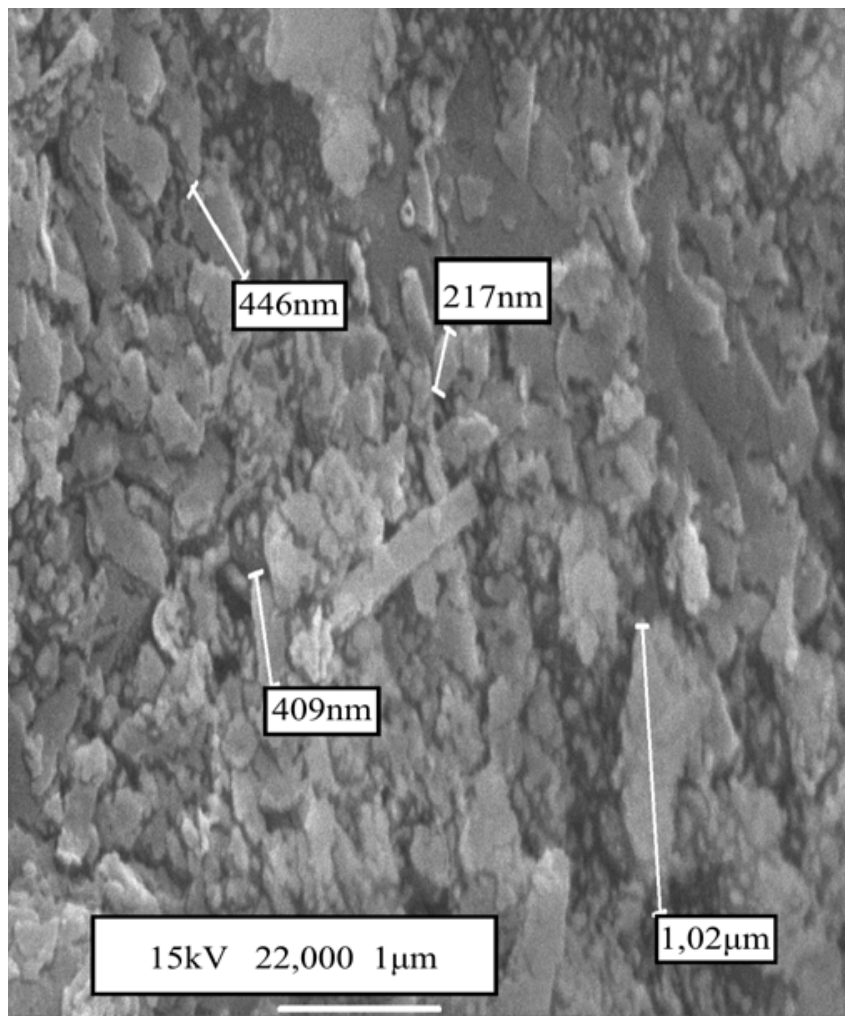

Figure 3. SEM image of HUGMA filler 


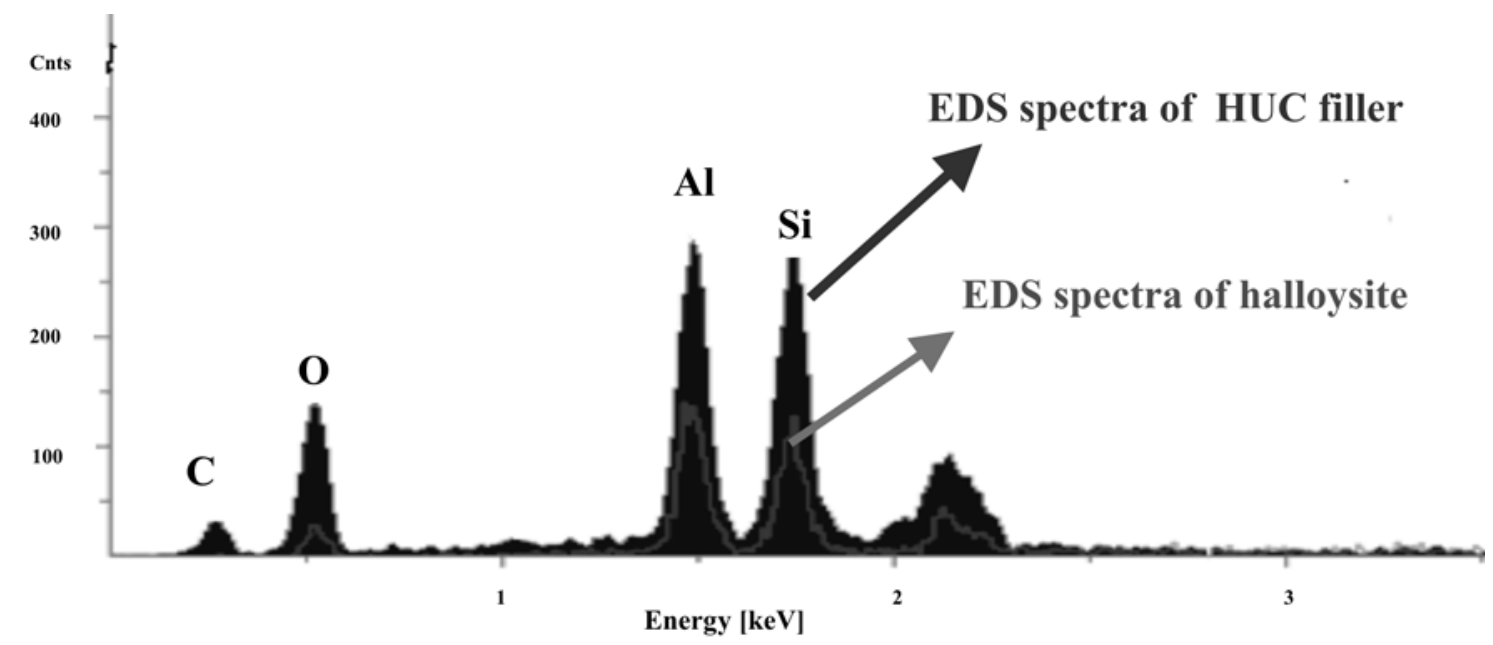

Figure 4. Spectra of EDS analysis of HUC filler

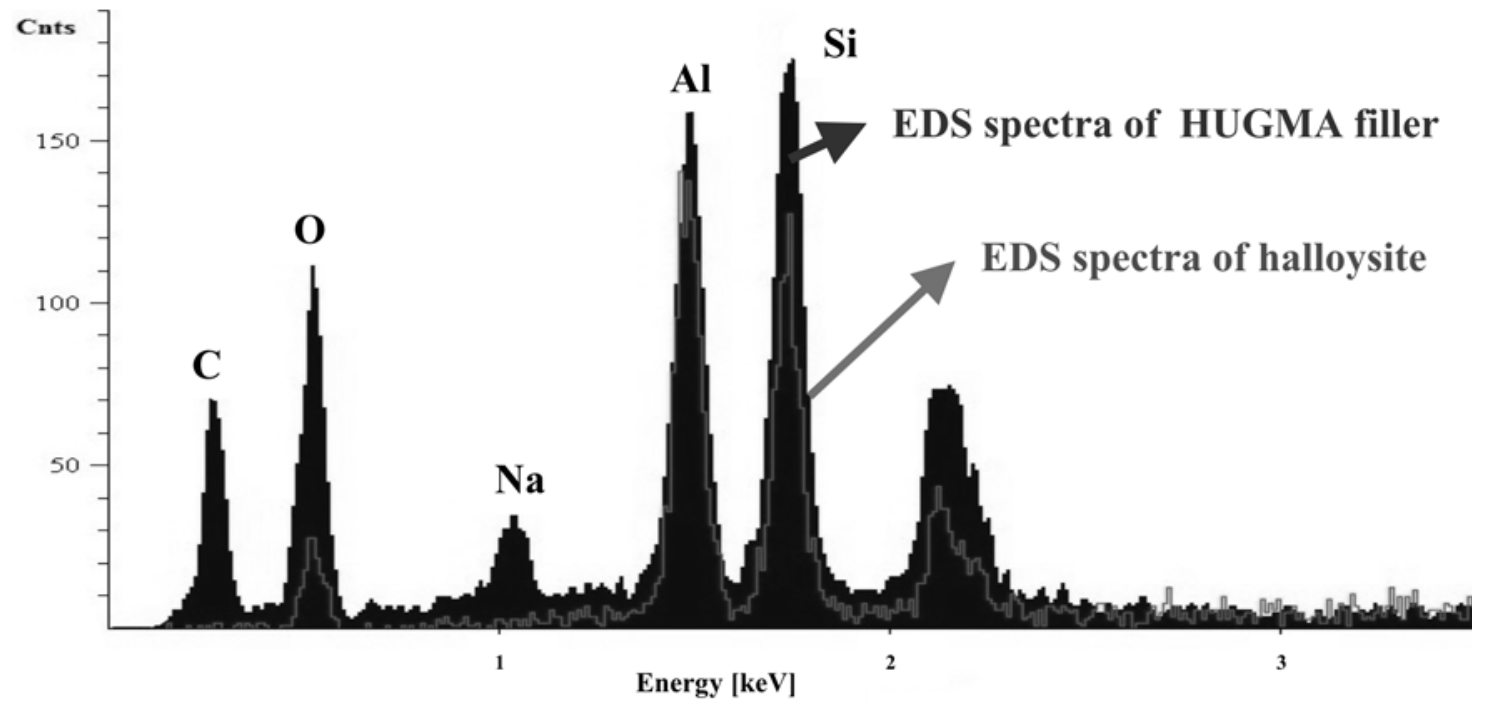

Figure 5. Spectra of EDS analysis of HUGMA filler

confirmed that the addition of modified halloysite to epoxy resin and a further curing led to the product which did not differ in thermal resistance from the cured unmodified resin. In the case of the modification with halloysite/gelatin, the maximum degradation temperature was even higher. This indicates a co-curing of the hybrid filler (the presence of an amine group in it). The increase in Tg observed in the samples indicated an accelerative influence of the applied fillers on the crosslinking of the resin. The obtained results are presented in table 4 .

\section{$\underline{\text { SEM analysis }}$}

SEM images of epoxy resin modified with $3 \mathrm{wt}$. \% of halloysite/gelatin, halloysite/OCPD and halloysite/Surlyn show the formation of a heterogeneous structure with well dispergated fillers and good interphase adhesion. The dispergation of the above-mentioned fillers is better than in the case of halloysite/colophony or halloysite/GMA.

\section{Mechanical properties}

Mechanical properties of the epoxy resin/modified halloysite composites are shown in Table 5. To our surprise, adding merely $3 \mathrm{wt} \%$ of modified halloysite into epoxy increased its impact strength by 6 times from $2 \mathrm{~kJ} / \mathrm{m}^{2}$ (neat epoxy) to $12 \mathrm{~kJ} / \mathrm{m}^{2}$ ( the composite with HUC). Such great improvement is comparable to the toughening effect of rubbers $^{\mathbf{8}}$, but the halloysite toughening was achieved at a much lower filler concentration. Moreover, using rubbers to toughen a polymer always scarifies other desirable properties such as modulus, strength and heat resistance. The flexural modulus and strength even had slight increases. Table 5 shows that the flexural strength of the epoxy/modi-

Table 4. Thermal properties of epoxy resin containing 3 wt. $\%$ of fillers

\begin{tabular}{|c|c|c|c|c|}
\hline \multirow[b]{2}{*}{ Name of composite } & \multirow[b]{2}{*}{ Type of modifier } & \multirow{2}{*}{$\begin{array}{c}\mathrm{DSC} \\
\mathrm{Tg}\left[{ }^{\circ} \mathrm{C}\right]\end{array}$} & \multicolumn{2}{|l|}{ TG } \\
\hline & & & Max. degradation temperature $\left[{ }^{\circ} \mathrm{C}\right]$ & $\begin{array}{l}\text { Weight loss } \\
\text { in } 700\left[^{\circ} \mathrm{C}\right],[\%]\end{array}$ \\
\hline ER & - & 103.0 & 366.0 & 9.5 \\
\hline 1 & HUG & 114.5 & 368.0 & 9.0 \\
\hline 2 & HUOCPD & 118.0 & 362.0 & 12.0 \\
\hline 3 & HUS & - & 365.0 & 13.0 \\
\hline 4 & HUC & 112.0 & 399.0 & 12.5 \\
\hline
\end{tabular}


Table 5. Mechanical proprieties of epoxy resin/modifier

\begin{tabular}{|l|c|c|c|c|c|c|}
\hline $\begin{array}{l}\text { Names of } \\
\text { composites }\end{array}$ & Type of modifier / \% contain & $\begin{array}{c}\text { Charpy } \\
\text { Impact } \\
{\left[\mathrm{kJ} / \mathrm{m}^{2}\right]}\end{array}$ & $\begin{array}{c}\text { Tensile strength } \\
{[\mathrm{MPa}]}\end{array}$ & $\begin{array}{c}\text { Flexural strength } \\
{[\mathrm{MPa}]}\end{array}$ & $\begin{array}{c}\text { Flexural strain } \\
{[\mathrm{mm}]}\end{array}$ & $\begin{array}{c}\text { Flexural } \\
\text { modulus }[\mathrm{MPa}]\end{array}$ \\
\hline 0 & $\mathrm{ER}$ & 2.0 & 40.0 & 64.0 & 2.8 & 2470.0 \\
\hline 1 & $\mathrm{HUG} / 3$ & 6.2 & 35.0 & 68.0 & 2.7 & 2481.0 \\
\hline 2 & $\mathrm{HUOCPD} / 3$ & 5.2 & 33.0 & 99.0 & 2.3 & 3213.0 \\
\hline 3 & $\mathrm{HUS} / 3$ & 8.8 & 37.0 & 87.0 & 3.8 & 3618.0 \\
\hline 4 & $\mathrm{HUS} / 5$ & 8.8 & 40.0 & 74.0 & 3.8 & 3530.0 \\
\hline 5 & $\mathrm{HUC/3}$ & 12.0 & 48.0 & 96.0 & 2.3 & 2618.0 \\
\hline
\end{tabular}

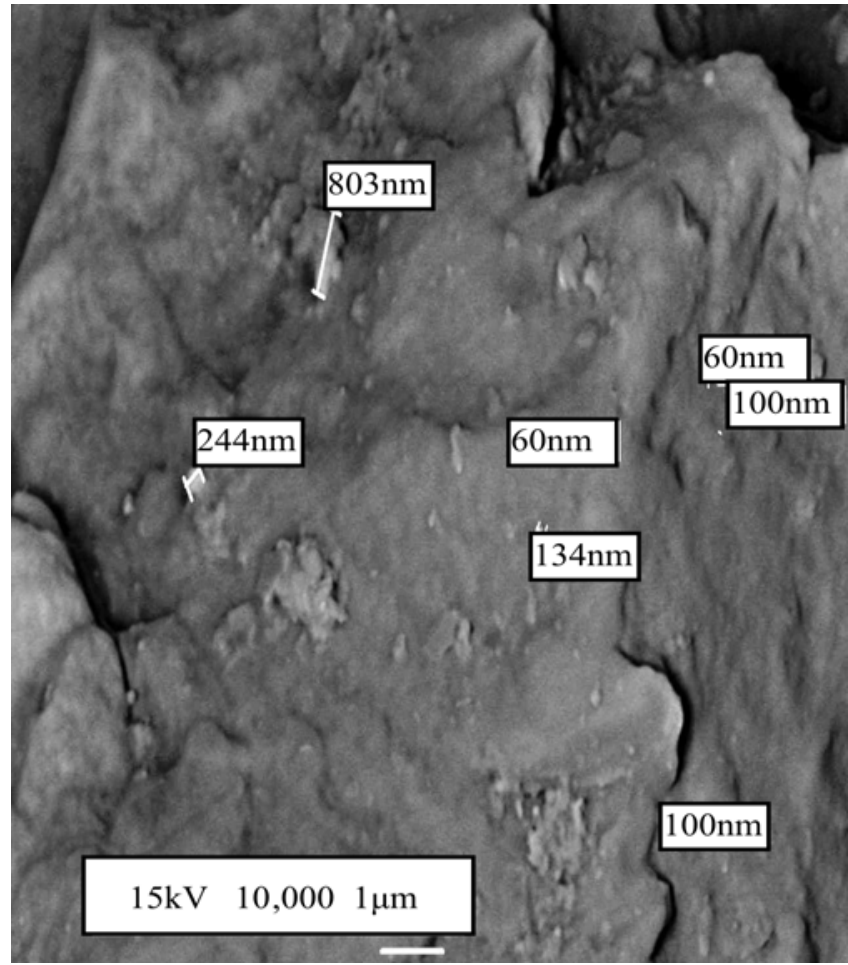

Figure 6. SEM image of ER/HUG composite

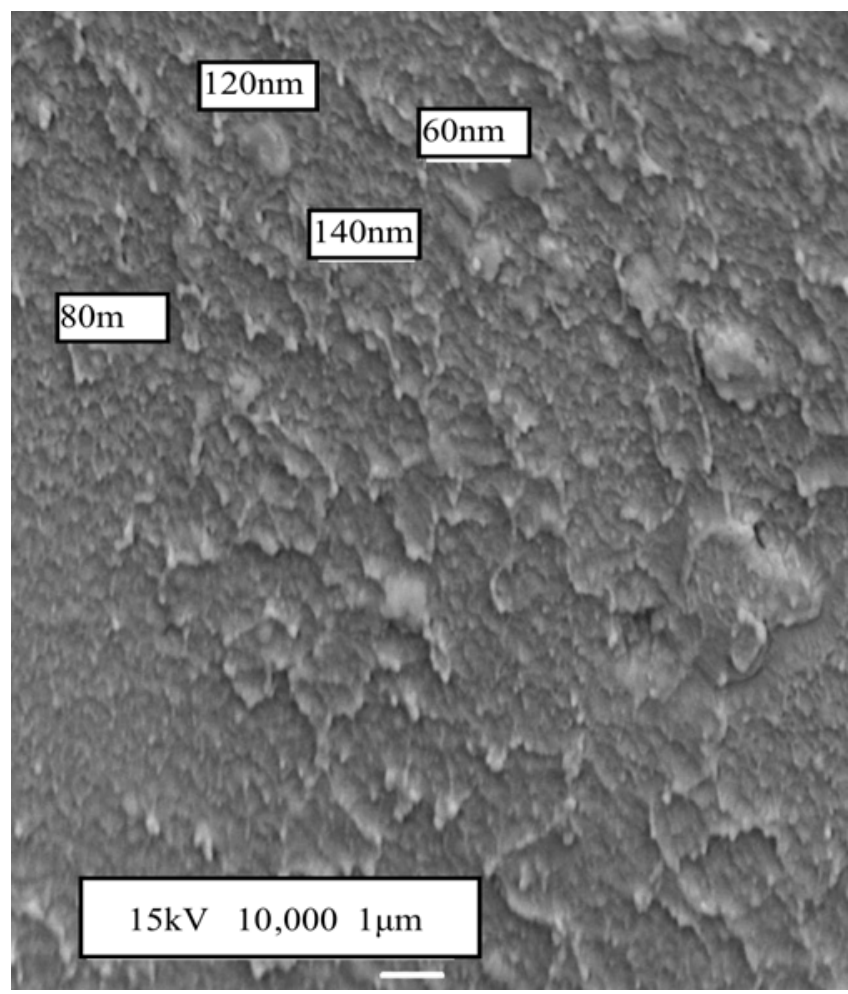

Figure 7. SEM image of ER/HUS composite

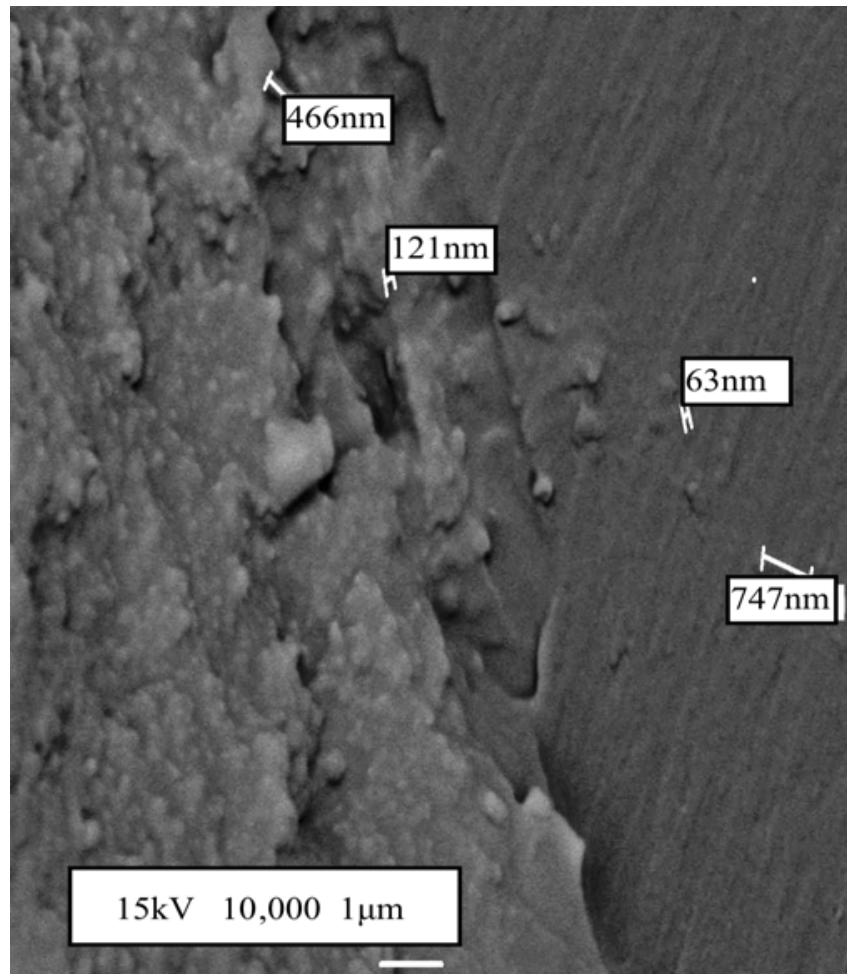

Figure 8. SEM image of ER/HUOCPD composite

fied halloysite composites increased from $64 \mathrm{MPa}$ (neat epoxy) to $96 \mathrm{MPa}$ (3 wt \% of HUC) and $99 \mathrm{MPa}$ (3 wt \% of HUOCPD) and $87 \mathrm{MPa}(3 \mathrm{wt} \%$ of HUS). This table indicates that the flexural modulus of the epoxy/modified halloysite composites increased from $2470 \mathrm{MPa}$ (neat epoxy) to $2618 \mathrm{MPa}$ (3 wt \% of HUC) and $3213 \mathrm{MPa}(3 \mathrm{wt} \%$ of HUOCPD) and $3618 \mathrm{MPa}$ (3 wt \% of HUS) Compared with other inorganic filler modified epoxy composites reported in the literature, the toughening effect of modified halloysite is still very impressive.

\section{CONCLUSIONS}

The preparation and application of a series of halloysite based modifiers in the filling of epoxy resin filling have been presented. The chosen modification method was found to be effective in obtaining active fillers. Structural analysis, especially SEM/EDS and PCS methods confirmed an addition layer on the halloysite surface of an organic layer derived from the applied modifying compound. It was confirmed that ultrasound treatment prior to chemical modification ensures better modification results. The modified halloysite was applied in filling the epoxy resin/curer in $3-5 \mathrm{wt} \%$. proportions. Structural analysis confirmed the occurrence of the interphase interaction in the polymer matrix/modified system. Thermal analysis also confirmed 
an increased thermal resistance of the final product evident in the higher degradation temperature of all the obtained composites and an increase in the glass temperature of the epoxy resin/modifier composites. The determined mechanical properties indicate an advantageous influence of the filler on increasing the resistance of the epoxy resin, primarily, the impact strength respective of the type and amount of the added halloysite increases. An increased amount of the filler, however, hinders the resin processing due to an increased viscosity of the composite.

\section{LITERATURE CITED}

1. Deng, S., Zhang, J. \& Ye, L. (2009). Halloysite-epoxy nanocomposites with improved particle dispersion through ball mill homogenization and chemical treatment, Composites Sci. and Tech .69, 2497-2505. doi:10.1016/j.compscitech. 2009.07.001.

2. Ye, Y., Chen, H., Wu, J. \& Ye, L. ( 2007). High impact strength epoxy nanocomposites with natural nanotubes, Polymer, 48, 6426-6433. doi:10.1016/j.polymer.2007.08.035.

3. Polish Committee for Standardization (1998). Polish Standards: Plastics - Determination of tensile properties. Part 1 - General principles. PN-EN ISO 527-1. Poland.

4. Polish Committee for Standardization (1998). Polish Standards: Plastics - Determination of tensile properties. Part 2 - Test conditions for moulding and extrusion plastics. PN-EN ISO 527-2. Poland.

5. Polish Committee for Standardization (1998). Polish Standards: Plastics - Determination of flexural properties. PN-EN ISO 178. Poland.

6. Polish Committee for Standardization (2001). Polish Standards: Plastics - Determination of impact strength. Part 2: The instrumental methods. PN-EN ISO 179-2. Poland.

7. Mandalia, T. \& Bergaya, F. (2006). Organo clay mineralmelted polyolefin nanocomposites Effect of surfactant/CEC ratio, J. of Physics and Chemistry of Solids, 67, 836-845. doi: 10.1016/j.jpcs.2005.12.007.

8. Ratna, D., Becker, O. \& Krishnamurthy, R., (2003). Nanocomposites based on a combination of epoxy resin, hyperbranched epoxy and a layered silicate, Polymer, 44, 7449 -7457. doi:10.1016/j.polymer.2003.08.035. 